\title{
O crime popular: publicidade literária e regeneração na Primeira República ${ }^{1}$
}

\author{
The popular crime: literature's publicity and regeneration \\ culture in Brazil's First Republic
}

\author{
Lucas Trazzi de Arruda Mendes ${ }^{2}$
}

RESUMO

Este artigo nasceu de algumas apreensões a respeito do contexto sociocultural de publicação do romance-folhetim Memórias de um rato de hotel, publicado pelo cronista-jornalista João do Rio no jornal Gazeta de Notícias do Rio de Janeiro em 1911-1912, romance que é considerado por nós como um exemplar de literatura de crime através do qual se pretendeu investigar e refletir a respeito da figura do crime e do criminoso neste período. No intuito de pensar as tensões do campo cultural e artístico em que nosso objeto de análise foi publicado, aqui procuramos destacar a relação entre uma "cultura da regeneração", que propunha pensar e reorganizar sua sociedade, com uma "cultura de massa" que transformava o meio jornalístico. Assim, apresentamos alguns comentários em torno das notícias sensacionais sobre crimes que eram publicadas nos jornais do momento juntamente com histórias ficcionais com a mesma temática; ao mesmo tempo em que procuramos compreender uma influência "maligna" que era atribuída a estas publicações nas falas de alguns representantes influentes das correntes cientificistas e, ainda, observar uma função social moral e pedagógica que era conferida aos jornais, sempre no intuito de resgatar ou regenerar a população considerada doente e assim sanar os problemas nacionais.

Palavras-chave: Literatura de crime. Primeira república. Regeneração. Romance-folhetim. Realidade macabra.

\section{ABSTRACT}

This article is based in partial conclusions of our research about crime and delinquency in the nineteenth century Brazil. Making use of crime literature from the period as historical reference in our investigation,

10 presente artigo é uma versão resumida de algumas apreensões referentes ao primeiro capítulo, A sensação do delito: crime e publicidade literária na Paris Tropical, de nossa dissertação, a qual encontra-se em processo de conclusão com título provisório de As Máscaras do Crime: destino, morbidez e carnaval nas memórias de um rato de hotel.

2 Mestrando em Historia Social pela Universidade Estadual de Londrina (UEL) sob a orientação da Profa. Dra. Célia Regina da Silveira. 
more specifically João do Rio's work of fiction Memórias de um rato de hotel, this present article has the intention to comment the literature field in which this novel was published, admiring the popularity of crime as source of sensational novel and news report content. Simultaneously, we intend to notice some comments of the intellectual people, which influenced the republican regeneration project, about this literature and newspaper publishing logic, observing an "illness" condition that appears to be attached to this crime theme literary-newspaper works.

Keyword: Crime literature. Journal literature. First republic. Regeneration project. Scare reality.

As considerações deste artigo nasceram da necessidade de compreender aspectos relevantes do contexto histórico de publicação do romance-folhetim de João do Rio, Memórias de um rato de hotel, a vida de Dr. Antônio contada por ele mesmo, publicado no jornal Gazeta de Notícias no final de 1911 e início de 1912. Foco de nossa pesquisa de mestrado, a análise do folhetim acabou se mostrando uma fonte relevante para tecer compreensões a respeito da figura do crime e do criminoso no período histórico. Isso por se pretender tratar das memórias "verídicas" de um rato de hotel conhecido como Dr. Antônio, gatuno de "fina figura" e "alta classe" que se hospedava nos melhores hotéis do Rio de Janeiro e realizava furtos contra os demais hóspedes.

Tratando do universo suburbano do crime da capital federal, por vezes enaltecendo desvios morais e criticando a norma vigente, em nossa investigação pareceu-nos necessário entender esse romance como uma expressão peculiar de literatura de crime ${ }^{3}$. Além disso, entendemos este livro de memórias como uma manifestação cultural com características comuns àquelas literaturas populares ${ }^{4}$ compreendidas como romances de sensação. Isso por demonstrar uma narração de "gancho" típica de novelas literárias e que procurava "fisgar" o leitor para o próximo capítulo; além de artifícios descritivos que privilegiassem o excitamento de sensações no leitor que, nas obras de João do Rio, quase sempre se manifestavam através da descrição de estados psicológicos perturbados e paradoxos morais.

Não tendo pretensão de analisar as memórias do Dr. Antônio diretamente aqui, este artigo foi resultado do esforço de compreender o contexto histórico de publicação deste livro, tecendo observações sobre as disposições socioculturais do momento. Para isso, focamos nossa análise em dois níveis ou discursos sociais diferentes do período. Pois além

3 Aqui compartilhamos da expressão também utilizada também por Ana Gomes Porto (2009) para se dirigir a todo tipo de narração ficcional que se detinha sobre o crime e o criminoso entre 1870-1920. Atitude que tornaria o termo uma subcategoria de amplitudes, embora em sua grande maioria acabem por coincidirem com alguns critérios narrativos comuns a outros "tipos" de romance de sensação.

4 Neste artigo, procuramos abordar essa popularização da literatura através do cunho mercadológico observado por Alessandra El Far (2004) e da admissão artística de Marlyse Meyer (1996). Através da crítica historiográfica da primeira e da crítica literária da segunda, procurou-se observar a emersão de um grande público consumidor em relação ao mercado livreiro do período, algo que trouxe consequências para o campo literário. Como uma participação mais intensa do público leitor no papel de gosto ou expectativa de leitura para a oferta diária de consumo cultural publicada nos jornais. E que daria nascimento àquilo que ficou conhecido como romance de sensação, sendo este o tipo de história que buscava fisgar o público através de artifícios narrativos de efeito que criassem emoções fortes e excitassem os nervos do leitor. 
de procuramos apreender uma lógica de mercado literário que parecia inclusive transformar os mecanismos culturais de publicação (de livros e jornais) na cidade do Rio de Janeiro, propomos refletir também à respeito de conteúdos reincidentes de discursos sociais sanitaristas. Os quais se tornavam instrumentos de neutralidade científica do Estado num seu projeto de regeneração física e moral da urbe carioca, e que acabariam por tecer noções específicas a respeito do povo brasileiro e uma sua inclinação a criminalidade ${ }^{5}$.

Embora discursos sociais diferentes - um ligado a publicação de folhetins e outro ligado às questões nacionais do período -, em nossa análise propôs-se observar um possível "compartilhamento" de perspectivas e conteúdos entre os dois âmbitos, refletindo a respeito de alguns aspectos similares entre esse projeto de regeneração republicano e o cenário literário-jornalístico em seu feitio mais mercadológico.

Segundo nossas observações, estas duas expressões culturais do momento pareciam, cada qual a sua maneira, dimensionar algumas concepções ou orbitar em torno de noções diferentes (mas não excludentes) a respeito do "povo" da capital republicana que, por um simbolismo pretendido na época, deixaria ver-se enquanto povo do Brasil.

Ainda, segundo essa nossa lógica comparativa, acabou-se por destacar como essas diferentes noções de povo brasileiro pareciam se ligar, de alguma maneira, ao interesse pelo crime e à condição de criminoso: seja nos ditames daquele projeto republicano que tornava a regeneração do delinquente, do degradado, do contaminado pelo "germe" do crime, o caminho para a edificação da nação brasileira; ou nos condicionamentos do cenário literário-jornalístico da primeira década do século $\mathrm{XX}$, onde conteúdos a respeito do crime enquanto sensação literária - e noções a respeito do povo - no papel de um mercado consumidor com um gosto exigente - relacionavam-se de maneira a dar razão às publicações dos jornais.

Dessa maneira, em nossa perspectiva uma investigação que se coloque no caminho de estudar essa espécie de popularidade ou "audiência" da figura do crime ou do criminoso nesses dois âmbitos da produção cultural do período - levando em conta seus campos de tensão específicos - seria uma que procuraria igualmente supor elos de compartilhamento possíveis entre esses dois discursos sociais. Não apenas no sentido de observar como poderia ter ocorrido este compartilhamento ou propor sentidos e significados que pareciam "predominar" no universo cultural de um momento histórico. Mas sim no percurso de melhor compreender como cada um desses âmbitos sociais pareciam se apropriarem de conteúdos latentes da sociedade e, compartilhando ou não acepções específicas de cada área, os reelaboravam de acordo com suas necessidades discursivas "internas".

5 Cenário histórico trabalhado por Sydney Chalhoub $(2001,2006)$ e Lilia Schwarcz (2005) e comumente entendido, por esses e demais pesquisadores do período, como período da "regeneração nacional". 
Assim, neste artigo procuramos mais por discorrer e exemplificar alguns dos procedimentos de uma lógica de jornal que tinha o intuito de tornar sensacional o conteúdo de suas matérias e, filiadas às notícias de crime, prezar por atrair seu público leitor; como de alguns comentários específicos por parte de algumas personalidades do período a respeito dos folhetins de crime que eram publicados nesses periódicos de acordo com a mesma lógica mercadológica. Sempre no sentido de procurar analisar as maneiras com que os dois níveis daqueles discursos sociais - o da publicação de notícias e folhetins nos jornais, e o do cientificismo da regeneração nacional - acabavam por se inter-relacionar nesse universo cultural.

\section{O crime que o povo gosta: a realidade macabra nos jornais}

No intuito de estruturarmos nossa pesquisa nas propostas acima comentadas, procuramos tecer uma análise que procurasse admirar a ascensão de um mecanismo cultural do jornal o qual procurava basear suas publicações direcionando-se através daquilo que Dominique Kalifa propôs enquanto autofagia cultural. Ou, em outras palavras, desejo do público de ler nos periódicos notícias e histórias ficcionais que, de alguma maneira, tivessem relação com o universo urbano em que viviam, levando os jornais a mudar seu caráter arbitrário e pedagógico para tornarem-se cada vez mais representativos - das expectativas culturais do público popular que procuravam admitir como clientela - e narrativos.

Ao mesmo tempo e chegando a observações similares às do historiador francês, Alessandra El Far, Marlyse Meyer e Ana Gomes Porto apontaram-nos observações a respeito de como esse mecanismo cultural emergente parecia condicionar o conteúdo de suas publicações, sejam eles notícias nos jornais ou mesmo contos, romances e crônicas publicadas em seus rodapés, misturando "verdade" e ficção segundo formulações que procuravam tornar sensacionais - no termo comentado por El Far - sua leitura. Aspecto mercadológico que indissociavelmente teria efeitos estilísticos e temáticos e que daria origem ao que entendemos por romances de sensação.

Sendo estes aquelas histórias cuja intenção era a de mexer com os nervos do leitor, o romance de sensação poderia ser uma categoria literária, tanto mercadológica quanto artística, subdividida em variadas expressões - se nesse ato um investigador encontrasse maior facilidade para seu estudo e apreensão. Todas essas ocupando os espaços de publicação de acordo com periódicos e tipografias específicos, sendo uma ou outra dessas subcategorias mais expressivas em relação às expectativas do público e, portanto, mais aceitas e recorrentes nos diferentes locais de exposição. 
Segundo um observador da época, alguém que em nosso estudo não aparece somente devido ao acaso de seu comentário, uma dessas expressões literárias na qual o público leitor parecia mais concentrar suas expectativas teria mesmo raízes históricas em nossa sociedade. Como aponta João do Rio em crônica a respeito do que se lê nas ruas da capital, publicada no jornal Gazeta de Notícias do Rio de Janeiro em 1906:

Os livros, porém, de grande venda ficam sempre os mesmos. Nós não gostamos de mudar em coisa nenhuma, nem no teatro, nem na paisagem, nem na literatura. [...] Desde 1840, o fundo das livrarias ambulantes, as obras de venda dos camêlos têm sido a Princesa Megalona, a Donzela Teodora, a História de Carlos Magno, a Despedida de João Brandão e a conversa do Pai Manuel com o Pai José - ao todo uns vinte folhetos sarrabulhentos de crimes e de sandices. (RIO, 2008, p. 87)

Folhetos de "crimes e sandices" que, absorvidos pela lógica autofágica do jornal, viriam figurar como grande intermediador entre as expectativas do público leitor popular e o conteúdo de publicação no jornal. ${ }^{6}$

Indo ao encontro da lógica mercadológica e estilística do romance de sensação, Dominique Kalifa também expõe a importância dessas histórias de crime para a edificação daquele paradigma representativo do popular no jornal e, portanto, para a configuração da cultura de massa $^{7}$ que emergiria nas primeiras décadas do século XX.

Em relação ao lugar do crime nesse paradigma, eu gostaria de sublinhar duas coisas: em primeiro lugar, o crime era um motivo tradicional, de longa data, de representação popular, desde os jornais ocasionais do Antigo Regime, as folhas avulsas, os panfletos. Há na literatura de colportagem um interesse popular pela transgressão, pela ruptura social, que é extremamente importante e que reencontraremos quando os jornais de grande tiragem recuperaram esse imaginário. A segunda questão é que o crime é um acontecimento histórico popular; ele é esse fato que ocorre de repente na vida das pessoas ordinárias, suscitando nelas o inesperado, o extraordinário, o acontecimento - o histórico, portanto. Daí resulta que essas histórias de crime, que são

6 Embora, excetuando talvez a Despedida de João Brandão - nome adotado por criminoso do século XIX e popular nos folhetins brasileiros do período (PORTO, 2009, p. 44) -, esses folhetins não possam ser integralmente admitidos na subcategoria de literatura de crime, eles devem ser vistos, entretanto, como um indício de uma constante do interesse de leitura do povo carioca baseado nas sensações ligadas ao crime e a violência. Motivo tradicional da literatura popular europeia e brasileira, como veremos adiante, que aportaram no Brasil em 1840 e se fixavam a partir de 1870 (PORTO, 2009, p. 44-46).

7 A emersão de uma cultura de massa nos jornais foi pensada por Kalifa mais como uma lógica vetorial que parte de uma mudança na cultura de publicação dos paradigmas de um jornal do que da necessidade de um público consumidor "volumoso" em si. Assim, ponderando o fim do caráter arbitrário de publicação e admitindo a emersão de uma lógica autofágica, é que pensamos ser possível "transferir" compreensões à respeito desta "cultura" para paragens brasileiras. 
tradicionais e que serão veiculadas por um dispositivo editorial cada vez mais maciço, são também histórias que contam às pessoas ordinárias, aos leitores ordinários, qualquer coisa de suas próprias vidas, de suas próprias histórias. (KALIFA, 2012, p. 187).

Embora realizadas em relação a outro cenário social e literário - a Paris das reformas de Haussman -, estas observações do historiador francês parecem competentes também ao estudo do universo social carioca do momento devido a certas tendências e aproximações entre aquilo que a Paris da belle époque havia vivido, e que continuaria vivendo por prolongamento histórico no século XX, com o que o Rio de Janeiro da regeneração vivenciou no momento. Seja devido a uma espécie de irradiação que partia da Europa progressista do período aos mais recônditos cantos do mundo, como também devido aquele esforço por parte da elite republicana do Brasil de preparar o terreno nacional para que estas concepções de avanço eurocêntrico aportassem em quase todos os âmbitos da vida social brasileira.

Portando-se contra uma história comparativa de "laboratório" (KALIFA, 2012, p. 188), Kalifa propõe que ao estudo da História uma análise que se arme da comparação entre dois universos sociais interessa apenas no âmbito daquelas sociedades que se deixaram influenciar entre si ao longo do tempo, circulando ideias e concepções que sofreriam releituras aos serem "transferidas" de um lugar social, seja este um país diferente ou um nível social variado, para o outro. No caso de estudo da relação entre Brasil e Europa - mais especificamente, ideias e práticas que se tornaram influentes na França e na Inglaterra e que dai irradiaram -, esse exercício analítico já foi feito mais do que satisfatoriamente em variados âmbitos da historiografia e da crítica literária por investigadores nacionais e estrangeiros. ${ }^{8}$

No caso específico da emersão da relação entre crime e cultura de massa, assim como Dominiqui Kalifa, acreditamos ser "interessante pensar as transferências culturais ou sociais" (KALIFA, 2012, p. 189), procurando assim "ver efetivamente como, quando os modelos circulam - isso é muito claro em matéria policial, mas também cultural e jornalística -, as proposições são trabalhadas, adaptadas, ajustadas às condições culturais locais" (KALIFA, 2012, p. 189). Sempre remontando a análise, quando necessário, no sentido da influência e da adaptação de conteúdos que, de alguma maneira e por algum

8 Entre a bibliografia citada ao longo do artigo, acrescentaríamos o trabalho de Jeffrey Needell sobre a belle époque tropical brasileira (1993). 
motivo, acabaram reincidindo e aportando em variados contextos de um período histórico aproximado.

Compreendendo a trajetória do romance-folhetim da Europa para nosso país - percalços estudados por Marlyse Meyer -, entendemos que o motivo tradicional do crime ao qual faz referência Kalifa e que observa João do Rio na capital devia mesmo ter figurado como uma constante na emersão daquela mecânica de publicação nos jornais e nas tipografias.

Como apontou Ana Gomes Porto, esse interesse a respeito dessas histórias escabrosas nascia concomitantemente a uma popularidade de reportagens sobre crimes, mistérios e escândalos reais - tanto no Brasil como na Europa -, e que estas notícias se tornavam mesmo mote ou tema para enredos imaginativos para a produção literária do primeiro com certa constância.

Por exemplo, em relação ao conteúdo sensacionalista das notícias de jornal, se folheássemos um exemplar do jornal Gazeta de Notícias do Rio de Janeiro em qualquer ano da primeira década do século $\mathrm{XX}$, não raramente nos depararíamos com manchetes e notícias com títulos extraordinários como "BESTA HUMANA!", acompanhada dos dizeres rapidamente explicativos sobre a "MÃE QUE ESQUARTEJA O PRÓPRIO FILHO", mais a curiosa informação de que "a cabeça da vítima denuncia o próprio crime" e finalmente, como um convite a leitura da narração jornalística sensacional que se seguiria, faz-se questão de determinar esse boletim da urbe enquanto uma "REALIDADE MACABRA!". Tudo isso acompanhado, quando não da foto da cena do crime ou do criminoso, pelo menos com a imagem do Dr. Alfredo Pinto, chefe de política, destacada junto aos seus comentários colhidos a respeito da cena hedionda.

Mas o furo jornalístico, quando objeto de comoção do grande público, quase nunca se interrompia em apenas um informativo, figurando cotidianamente no jornal até que rendida a curiosidade do leitor e bem "rendido" o bolso do editor. Por isso, no dia dois de agosto de 1908 a matéria investigativa continuou, trazendo agora a "A confissão do hediondo crime"10 retornando sob a alcunha de "REALIDADE MACABRA" e mostrando de primeira mão uma foto de "Guida ${ }^{11}$ da Silva, a autora do bárbaro crime". Além da imagem fotográfica da "cabeça da criança, vítima do hediondo crime" e

9 Todos os dizeres entre aspas desse paragrafo referenciam a: Gazeta de Notícias. Rio de Janeiro, sábado 1 de agosto de 1908.

10 Gazeta de Notícias. Rio de Janeiro, domingo 2 de agosto de 1908.

$11 \mathrm{Ou}$ pelo menos foi o que conseguimos entender do nome da autora do crime no periódico que chegou a nossas mãos que, infelizmente, encontrava-se deteriorado exatamente na legenda da foto. 
também do telhado situado no "becco da Batalha" pelo qual a cabeça da criança fora lançada pela autora do crime na tentativa de se desfazer do corpo miúdo.

Mais sensacional ainda foi a cobertura do famoso caso da "MALA SINISTRA"12, "CRIME MONSTRUOSO DE S. PAULO AO RIO" que correu a nação também em 1908 e que ganhou grande destaque igualmente no Gazeta de Notícias do Rio de Janeiro. Sendo este acontecimento contemplado enquanto "Um crime horrível!", mas ao mesmo tempo aclamado como "Um crime empolgante e atroz!" pelas primeiras linhas de sua manchete, durante todo o mês de setembro (até onde pudemos averiguar) os relatos jornalísticos a respeito desse crime figuraram dia a dia no jornal. Cada notícia revivendo a sensação e apresentando novos detalhes em reportagens que disputavam, e não raramente ganhavam, o espaço das manchetes com as notícias sobre a famosa Exposição Nacional de 1908 que ocorria no Brasil na capital, sendo inaugurada também em setembro, e que atraia a atenção do mundo todo mas talvez nem tanto assim da curiosidade popular da própria cidade.

Muito interessante de ser observado é como a lógica de publicação das matérias relativas ao "crime da mala" parecia remontar a toda uma narrativa de novela no qual são apresentados os personagens de acordo com sua relevância para o caso, como Michel Traad, imigrante primeiramente acusado de cometer o delito e depois autor confesso; o negociante Elias Farhat, a vítima; entre outros personagens, como os delegados e demais responsáveis pela investigação, testemunhas, parentes, etc., cada qual ocupando sua fala no interesse de reconstituir a narração de um evento que era remontado todos os dias no periódico. Reconstituindo situações, cenários, questionando-se a respeito das pistas, do chapéu desaparecido de Farhat com o qual havia sido visto pela última vez... Entre outras descrições de maior ou menor relevância para a apresentação do caso ao público, cujo intuito parecia mesmo o de se criar a aura de sensacional em torno do ocorrido.

Afinal, não era todo dia em que um corpo era encontrado mutilado em uma mala... Embora o clima de realidade macabra que o jornal parecia querer fazer o seu leitor comprar talvez tivesse a intenção de propor o contrário, provocando alardes sensacionalistas a respeito da sociedade brasileira do momento. Até porque, quando um crime parecia esgotar seu material noticioso e assim interromper a renda de atenção do público, sempre aparecia outro para assumir o seu espaço no jornal. 
Em relação a esse mecanismo de substituição gradativo de notícias sobre crime, é possível citar algum exemplo ainda em setembro de 1908. Sendo este as reportagens reincidentes que admiravam o caso de duplo assassinato que ficou conhecido como "O NOIVADO DA MORTE"13 e que, no mesmo ímpeto narrativo, usava de imagens fotográficas, ilustrações e descrições muitas vezes hiperbólicas e tendendo à comoção para criar toda a atmosfera de sensação em torno do acontecimento escabroso.

A BESTA HUMANA, a MALA SINISTRA, O NOIVADO DA MORTE, entre outras chamadas de primeira página em relação ao crime, vinham então figurar no jornal com títulos mais do que expressivos que, em caixa alta e muita exclamação, gritavam pela atenção do leitor tanto quanto aquele apelo mercadológico que os romances de sensação procuravam provocar na tentativa de conquistar a curiosidade dos leitores.

Manchetes com títulos de livro de terror, transferindo aquela temática clássica ou motivo tradicional do crime e do horror para as notícias de jornal, armando-se de dispositivos caros à ficção e assim aparelhando a narrativa jornalística com uma densidade descritiva gerada e geradora da necessidade pelo sensacional nas páginas do jornal. Vindo o crime e sua "audiência", enquanto motivo popular - do gosto do povo e também como comentário sobre o povo -, configurar seu papel no mecanismo cultural de massa nos periódicos através da lógica de atração e sedução de leitores.

Mas o espaço do crime no jornal não se resumia apenas as manchetes. Pequenas reportagens com função de boletim informativo costumavam figurar ao longo de todo o corpo do jornal, muitas vezes aparentando grau de anedota sobre gatunos conhecidos, gangues de arrombadores, estranguladores, estupradores e muitos outros diferentes tipos de infratores que assombravam as ruas do Rio de Janeiro. Vindo das calçadas para o jornal, e do papel retornando às sarjetas...

Onde era o seu lugar, sendo o crime um acontecimento público (evento da rua) por excelência. $O$ mesmo espaço do leitor que, atentamente, devora a si mesmo nas páginas do jornal a procura do acontecimento histórico popular, aquele que acontece de súbito na vida nas pessoas suscitando a emoção do inesperado e do extraordinário (como pensou Kalifa). Processo autofágico de um desejo de si mesmo relido na máquina de notícias e sensações do novo jornalismo "representativo". 
Em nossa conta, aquele interesse popular pela transgressão ou ruptura social ao qual procurou apontar o historiador francês parecia estar em alta na sociedade carioca do momento, principalmente se pensarmos naquele aspecto autofágico proposto. Afinal, uma população que era criminalizada nas tendências determinantes de um discurso sócio-político com pretensões de oficialidade e neutralidade científica, com leis específicas que combatiam seus costumes e meios de sobrevivência até então, como era a do Rio de Janeiro da regeneração, em nossa análise não poderiam deixar de se interessar ou mesmo se identificar em certo grau com a figura do criminoso que era exposta nos jornais. Consumindo-a como quem se alimenta do próprio cotidiano, assistindo as ruas que habitavam ou nas quais passeavam cotidianamente tornarem-se celebridades da noite para o dia no jornal, devido mesmo a acontecimentos macabros e sensacionais que lá se passaram enquanto este mesmo leitor dormia ao lado.

Como visto, a realidade macabra pretendida de ser instaurada pelo jornal não se satisfazia apenas em torno do material "verídico" das notícias de crime. Tomando-as como mote, embora nem sempre diretamente, o crime ocupava também o espaço dos fatos diversos dos periódicos através de ficções macabras que tornavam seu palco de dramatização aquele cenário doméstico e urbano da das cidades - Paris, Londres, Berlim, Rio de Janeiro e outras Cosmópolis do período. Buscando sempre inserir o leitor nesta realidade que, afinal, era a sua própria, embora vista através da "lei da oferta e da procura" por notícias e sensação...

Demanda que, na expectativa de ser atendida pelos publicadores da capital, usava do crime e do criminoso como elemento central de criação deste procedimento de releitura da realidade comum aos leitores. Algo que, para os observadores atentos, poderia deixar transparecer uma espécie de estrutura de sentimentos ${ }^{14}$ ou imaginário social a respeito desta figura recorrente de interesse popular, tanto por parte de um mecanismo cultural de massa ${ }^{15}$ do jornal quanto de discursos sociais da intelectualidade do momento. Sendo este imaginário um "conjunto das produções, ficcionais ou não, que podem produzir uma concepção, ou uma representação da sociedade, e que será produtora de práticas sociais" (KALIFA, 2012, p. 186) no

14 Aqui fazemos referência ao termo conceituado por Raymond Willians (1989).

15 Nas apreensões de nosso estudo, compartilhamos do argumento desenvolvido por Dominique Kalifa (2012) ao conclamar que, embora ainda não existisse aquilo que se poderia chamar de "massa" no universo social francês - e também na sociedade brasileira -, o paradigma da cultura de massa estaria, entretanto, se instalando nos jornais e periódicos da França e do Brasil do período discutido. Sendo este paradigma aquele que procurava vender ao leitor um produto cultural resultante daquele seu desejo de autofagia, como comentado acima, sendo mais uma iniciativa dos meios de comunicação do momento a procura de se aproveitar de um mercado até então ignorado - como apontou El Far (2004). 
sentindo que estas são, portanto, "representações constitutivas do social, matrizes da sociedade" (KALIFA, 2012, p. 186) as quais o historiador, em seu "trabalho sobre os fait divers, sobre os romances, sobre a cultura de massa está sempre em busca das representações constitutivas de práticas sociais" (KALIFA, 2012, p. 186).

Maneiras de ver, ler e reler o mundo que, figuradas nos romances de grande circulação prenhes de componentes reincidentes, poderiam deixar relacionar elementos dos mais variados discursos sociais e, assim, trazer notoriedade para determinado componente possível de estar presente nessas representações constituintes da vida em sociedade.

Essas histórias de crime, portanto, não dizem algo apenas sobre quem as escreve. Mas também, em algum nível, sobre seu público consumidor. E esta asserção não foi um sentido que escapou a alguns observadores do próprio período, figurando mesmo como uma pretensão de análise em relação ao povo que lia essas histórias de conteúdos populares.

Vimos que a temática do crime, devido a sua demanda na lógica sensacional de mercado, acabaria por influenciar aquele setor da literatura brasileira que lidava com os nervos do leitor - como procurou demonstrar Ana Gomes Porto. Entretanto, "perguntando" à alguns observadores do período, procuramos refletir se o inverso desta relação não poderia ter chegado a acontecer, sendo o próprio crime - ou a criminalidade influenciada por esse tipo de literatura que usava do escabroso para despertar sensações no público.

Figura 1 - Primeira página do Gazeta de Notícias do dia 1 de agosto de 1908, trazendo ao público a "realidade macabra" através de notícias sensacionais. 


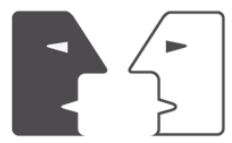

ANTÍTESES

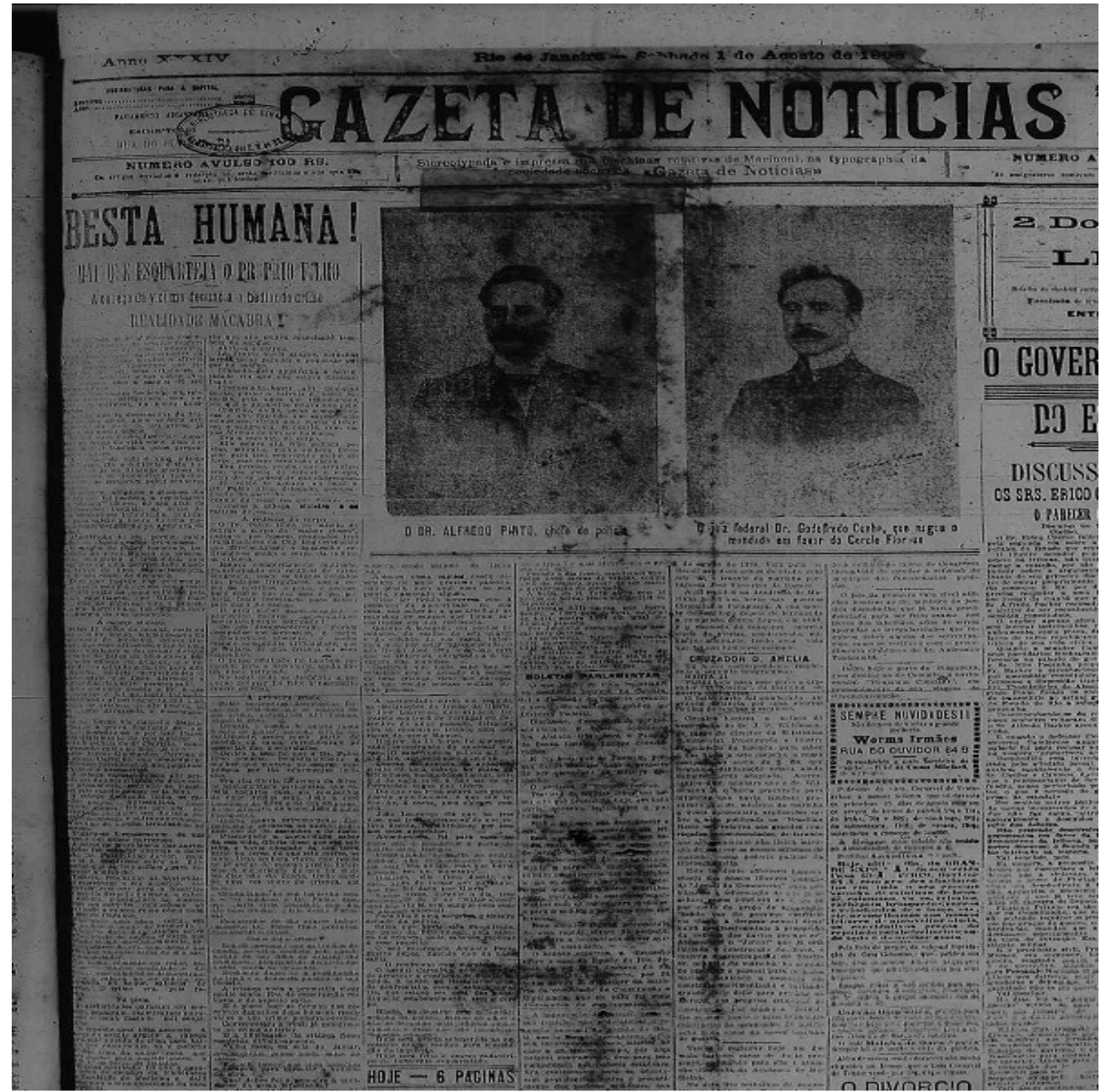

Fonte: Gazeta de Notícias, 1 ago. 1908. Arquivo Edgar Leuenroth (UNICAMP).

\section{Uma literatura condenada para uma população degenerada}

Algo haveria de ser dito e pensado a respeito desta tendência nada civilizada do público brasileiro - mas também europeu - em corresponder anseios e sentimentos daquela máquina cultural através da figura do crime e do criminoso. Muito comprada e 
acompanhada pelo leitor popular da época da regeneração, aqui refletimos a respeito dos diferentes motivos de inclinação desse povo a esse tipo de realidade macabra produzida pelos jornais.

Considerando o povo uma massa informe de pessoas dos mais variados segmentos sociais (altos e baixos) como propôs El Far (2004), aqui pensamos que o crime poderia figurar como elemento de interesse aglutinador de variadas temporalidades justamente porque esse tipo de romance de gosto popular compartilhava uma série de elementos reincidentes de um imaginário social que poderiam dizer coisas diferentes a cada altura da sociedade. Mudando sua mensagem de acordo com o público, mas sem mudar seu texto em vista deles, sendo que era publicado em formatos diferentes, de acordo com o bolso do leitor, mas com conteúdos idênticos (EL FAR, 2004, p. 12).

Entrando no âmbito da recepção, mas sem poder nos aprofundar nele com propriedade $^{16}$, partimos de suposições que pareceram pertinentes de acordo com discussões bibliográficas sobre o período. Às quais nos levaram a pensar o universo cultural do Rio de Janeiro do momento como um híbrido de práticas e expectativas sociais.

Como comentado anteriormente, certa parcela mais rasa da população brasileira (o populacho) poderia ansiar por este tipo de literatura no sentido da identificação com os conteúdos da história. De sua trama, pois para além de despertar os nervos, efeito caracteristicamente comum a todas as alturas da sociedade e que aguçava a curiosidade do leitor, essas histórias também poderiam despertar esse público para sentidos e significados talvez implícitos em certos conteúdos sociais ou dramatizações dos campos de tensão no qual vivia. Sendo o crime foco de interesse para essa gente no sentido em que parte dela se deixava estar ou ser vista na criminalidade - admitindo um argumento vindo de cima para baixo.

Assim, pensamos que este interesse poderia figurar também como uma espécie de resistência silenciosa por parte daquela população que tinha sua cultura e costumes, enquanto avessos à ideia de progresso e civilização ${ }^{17}$, criminalizados no período. Seja através da admiração dos gatunos, assassinos, contistas e demais personagens malandros que eram recorrentes nesse tipo de narração, muitas vezes os "heróis" das narrativas e que, até certo momento, tinham sucesso em burlar o "sistema" e tirar vantagem dos homens de bem da sociedade. Exemplos quase românticos do ato de "se portar" em relação ao mundo em um ambiente repressor.

Seja no sentido inverso exercitado por leitores do mesmo nível social. Os quais procuravam delimitar a figura dos degenerados enquanto uma exceção extraordinária em relação à população "comum" num momento em que os criminalistas pareciam propor o 
contrário a respeito do povo brasileiro. Ou seja, um movimento contrário à tendência de ser colocado no mesmo "saco" daqueles que se sentiram ameaçados pela moral da regeneração e criando assim um distanciamento identitário entre aqueles outros sujeitos que abraçaram a nova ética imposta pelo Estado republicano.

Também no sentido do exercício de diferenciação de imagens e autoimagens, já o leitor da elite financeira e intelectual da República talvez fizesse justamente o processo de leitura contrário: colocando todos aqueles que não compartilhassem tanto de seu status cultural como material, enquanto possíveis agentes do crime. Encontrando assim nessas narrações jornalísticas (e) ou ficcionais, uma maneira de autoafirmação numa disputa entre posições e legitimidades de discurso - a elite contra as classes pobres e, como desdobramento histórico, perigosas(CHALHOUB, 2006, p. 20-22).

Como observou Dominique Kalifa a respeito do cenário parisiense das reformas de Haussman, processo histórico francês no qual os idealizadores da regeneração carioca iriam inclusive se basear em seus próprios projetos, o crime e a delinquência iriam figurar "como transgressão da norma, produção cultural, e contenção política ao mesmo tempo saturando o espaço público parisiense" (KALIFA, 2004, p. 176) ${ }^{18}$. Causando grande comoção ao se tornarem uma temática de sucesso nos diferentes níveis da sociedade. Portanto, para o historiador, estudar a relação entre o crime e a cultura de massa evidenciada no momento seria uma investigação no sentido de analisar "como, e com que tipo de resistência [ou ausência dela] as representações do perigo" (KALIFA, 2004, p. 176) ${ }^{19}$, sejam estas dando-se em nível mais político, cultural ou artístico, "se tornaram haussmanizadas" (KALIFA, 2004, p. 176).

Em seus estudos, o historiador francês se propôs mesmo a estudar a importância das novelas de crime na perpetuação de imagens de criminalidade da capital francesa ao longo do século XX, muitas vezes ligadas aos próprios espaços físicos e sociais da topografia urbana. Solidificando mitos urbanos os quais, mesmo que em algum momento "baseados" em experiências reais com os lugares da cidade, perderiam sua referência de fato com as transformações materiais da capital. Mas não seus referenciais simbólicos perpetuados pelas novelas de crime que, por exemplo, davam continuidade a imagem do centro de Paris como um antro de delinquência quando este já havia sido "sanado" pelo esforço reformista francês. Demonstrando assim, portanto, uma "autonomia extraordinária das representações sobre Paris, e a habilidade de uma cidade que existiu no papel para levar uma vida própria" (KALIFA, 2004, p. 176) ${ }^{20}$ independente da realidade de fato. Mas totalmente interdependente

18 Tradução aproximada de "[...] as transgression of the norm, cultural production, and political contention all at the same - saturated parisiam public space".

19 (Trad.), "how, and with what kinds of resistance, the representations of danger gradually became "Haussmannized."

20 (Trad.) "remarkable autonomy of Paris representations, and the ability of a city that existed on paper to lead a life of its own." 
das realidades socioculturais que - tanto Europa quanto no Brasil da belle époque - nasciam do campo de tensões e disputas morais, simbólicas e práticas do momento.

Aqui entendemos que algo aproximado parecia acontecer no cenário da capital brasileira do momento, trazendo diversas comoções em relação ao crime e criminoso para o palco de dramatizações da vida social carioca. Pois a regeneração também se armava de um processo de reforma material e cultural da cidade, propondo transformar toda aquela velha estrutura de vielas estreitas sem rede de esgoto e cortiços superpopulosos da época do império, esqueleto falido para o universo republicado desejoso de progresso, no sentido de higienizar a população do Rio de Janeiro daqueles antros viciosos corruptores do corpo e do espírito. E assim sanar o povo brasileiro e condicioná-lo à labuta através de uma ética cientificista do progresso e uma moral do trabalho.

Esforço por parte da elite intelectual e científica do Brasil que, ao exemplo de Hussman, propunha destruir o velho Rio infectado pelo crime. Expulsando assim as "classes perigosas" das ruelas que eram botadas abaixo. Mas ao mesmo tempo influenciando profundamente na continuidade do interesse pelo crime por parte dos mecanismos jornalísticos da cultura de massa, os quais muitas vezes tomariam este processo de criminalização sensacional como mote literário.

Tema que, baseando-se nessa audiência que a delinquência - enquanto motivo literário popular já de longa data - continuava conquistando, permitiu a revitalização de imagens do submundo em Paris (KALIFA, 2004, p. 181). E que no Rio de Janeiro, através da influência europeia no âmbito das letras e das políticas públicas, tornou aceitável e até mesmo mercadológico explorar o cotidiano daquele povo que era degenerado pelos discursos sociais. Posição que abriu ao público popular daquele momento algumas fantasias em relação às "cavernas sociais" (KALIFA, 2004, p. 180) ${ }^{21}$ em que estes "degenerados" viviam. Propondo a possibilidade deste submundo - margem da sociedade, longe da civilização, o "wrong side of the right one" (KALIFA, 2004, p. 186) - emergir cotidianamente onde menos se espera.

Dessa maneira, aquela realidade macabra pretendida e generalizada pelo jornal poderia vir servir a diferentes segmentos da sociedade, trazendo níveis de leitura, posicionamento e envolvimento diferentes. Agradando ao leitor popular ao mesmo tempo em que lhe trazia justificativas para sua autoimagem, apropriadas de maneiras diferentes de acordo com os fatores diferenciados da vida de cada leitor, e ainda excitando-lhe os nervos e assim cumprindo o papel de bom entretenimento.

Mas se essas leituras tão populares eram compartilhadas por variados níveis da sociedade, que se apropriavam delas e "produziam" algo através delas, e que por trazerem 
elementos reincidentes de variados âmbitos da sociedade pareciam dizer muito a respeito de um imaginário social sobre o crime e do criminoso, não poderiam ter sido consideradas uma espécie de fator indiciário desta sociedade de leitores cariocas do período por parte daquela própria intelectualidade do momento? Aquela ligada ao cientificismo ou a regeneração e que tornava seu povo um problema a ser pensando e resolvido?

No sentido deste questionamento, várias outras perguntas poderiam ser desenvolvidas a partir dessa: o que essa obsessão ou demanda por cenas de crime poderia dizer a respeito de seu público consumidor? Ou melhor, não se questionava que tipo de influência essa literatura haveria de ter sobre o povo que a lia?

Em nossa apreensão, é justamente a respeito disso que nos aponta a continuação daquele comentário de João do Rio sobre estas literaturas de crimes e sandices:

\begin{abstract}
Essa literatura, vorazmente lida na Detenção, nos centros de vadiagem, por homens primitivos, balbuciada à luz dos candeeiros de querosene nos casebres humildes, piegas, hipócrita e malfeita, é a sugestionadora de crimes, o impulso à exploração de degenerações sopitadas, o abismo para a gentalha. Contam na Penitenciária que o Carlito da Saúde, preso a primeira vez por desordens, ao chegar ao cubículo, mergulhou na leitura do Carlos Magno. Sobreveio-lhe uma agitação violenta. Ao terminar a leitura, anunciou que mataria um homem ao deixar a Detenção. E no dia da saída, alguns passos adiante, esfaqueou um tipo inteiramente desconhecido. Só esse Carlos Magno tem causado mais mortes que um batalhão de guerra. A leitura de todos os folhetos deixa, entretanto, a mesma impressão de sangue, de crime, de julgamento, de tribunal. [...] Tudo quanto é inferior - a calúnia, o falso testemunho, o ódio - serve de entrecho a esses romances mal escritos. (RIO, 2008, p. 87-88).
\end{abstract}

Estimulo de sandices, o abismo para o leitor. Uma leitura de condenado, de preso, um produto que apesar do fato de que "diariamente e perpetuamente se vendem mais volumes que da Cannaã de Graça Aranha” (RIO, 2008, p. 87-88), vem figurar nesta crônica de João do Rio como uma literatura condenada. Cujos autores, "criminosos anônimos" (RIO, 2008, p. 8788) na fala sensacionalista do escritor, cometem o crime de se dedicar a esses romances mal escritos e perniciosos. Fator que levaria a própria realidade macabra pretendida pelo jornal e pelos romances de sensação tomar conta do comentário a respeito destas histórias, criminalizando por sua vez os autores desses romances mancomunados.

Comentário interessante de um cronista que, a sua maneira, iria quase seis anos depois dar sua contribuição toda peculiar ao conjunto deste tipo de literatura que condena ao publicar o romance folhetim sobre o Dr. Antônio. Observação tão pertinente ao contexto político, social e literário de publicação e que vem também reafirmar a necessidade de tonar 
sensacional - como substrato daquele mecanismo jornalístico de cultura de massa - a figura do crime e do criminoso "neste mortal período de desinfecções e higiene à outrance" (RIO, 2008, p. 87-88).

Uma guerra travada entre a ideologia da higiene física e moral dos discursos cientificistas contra as classes perigosas e suas práticas viciosas que essa própria ideologia determinou como problema nacional. Sendo, para alguns, essa literatura condenada por João do Rio mas plenamente absorvida pelo público, um perfeito exemplo da degeneração do povo como um todo. Pois o cronista carioca, como muitos outros do momento, era daqueles que se apropriavam de comentários especializados de ramos específicos das ciências do momento - como a antropologia e a psiquiatria - no intuito de dar propriedade às suas observações... Mas também no de trazer ao público comum, na função de jornalista, algumas tendências mais interessantes destes argumentos.

Assim, citando Césare Lombroso e outros membros da Escola Positiva de Direito Penal ${ }^{22}$ em variados âmbitos da antropologia do momento - inclusive a criminal - quando de seu interesse jornalístico de causar sensação, João do Rio acabou contribuindo para o compartilhamento de alguns elementos de variados níveis discursivos (representativos ou não).

Ao tipo de literatura "condenada" se debruçariam, inclusive, alguns daqueles cientistas mais notórios. Como foi o caso de Enrico Ferri, proeminente colaborador da Escola Positiva de Direito Penal fundada pelo próprio juntamente com Lombroso e Garófalo, e pai da sociologia criminal: ciência que somaria aos aspectos antropológicos propostos por seus colegas, enquanto determinantes do comportamento criminoso, os aspectos de influência social. Sendo este aspecto uma disposição que, segundo seus encaminhamentos, também poderiam ser apercebidos na literatura. Isso através da análise das imagens literárias produzidas sobre os criminosos, ou daquele gosto pelas leituras de crime do público popular que denunciaria tendências do comportamento social de determinado universo cultural.

Pois, segundo o criminalista, esta "ciência positiva consente em abandonar, às vezes, a atmosfera grave das salas acadêmicas, para ir renovar-se e fortificar-se ao ar livre, em contato com todas as formas real ou idealmente vivas da personalidade humana" (FERRI, 2001, p. 16). Ação que tem por objetivo sinalar "personificações artísticas de delinquentes às quais se possam aplicar os dados da antropologia criminal" (FERRI, 2001, p. 16). Pois a literatura, enquanto "reflexo irisado da vida" (FERRI, 2001, p. 21), teria sido por muito tempo

22 Instituição italiana fundada por Césare Lombroso, Erico Ferri e Rafael Garófalo e que muito iria influenciar a criminalística do momento. Articulada principalmente em torno das proposições científicas de Morel e Lombroso, a grosso modo o delito passou a ser encarado enquanto uma manifestação resultante de uma série de fatores condicionantes no criminoso, dizendo a ele respeito mas que escapavam ao controle do indivíduo. Nesta reflexão, a noção de degenerescência de Morel se combinaria com as determinações hereditárias e atávicas propostas por Lombroso no sentido de estruturar o pensamento daquilo que ficou conhecido como antropologia criminal, uma ciência que concentrava seus esforços numa interpretação sociológica, psiquiátrica e fisiológica do sujeito criminoso. 
a única manifestação humana a tentar compreender, através de uma "figuração material ou análise psicológica do delinquente" (FERRI, 2001, p. 21), a figura do criminoso nos aspectos intimistas de seu ser.

Tarefa na qual, segundo Ferri, teria vindo o comentário pertinente das disciplinas científicas da psicologia mórbida e da antropossociologia criminal corrigir os erros desta análise literária. Disparates que na arte seriam fruto das "exigências do público" (FERRI, 2001, p. 22), as quais raramente teriam estimulado seus autores a uma pesquisa mais profunda e verdadeira sobre o criminoso. Levando, desta maneira, o crime a ser na literatura "representado senão por suas encarnações mais típicas e menos ordinárias" (FERRI, 2001, p. 22) na ânsia de corresponder a uma ideia pouco racionalizada, mas mais interessante ao leitor ávido pela sensação e estímulo dos nervos.

Assim, no intuito de tecer comentário sobre a figuração do crime e do criminoso na arte e na literatura, Ferri procurou ainda analisar - à maneira de uma crítica sociológica da literatura - a relação entre público e publicador, destacando a importância dos jornais nesse processo todo enquanto caçadores de manchetes que seriam fabricadas pela máquina da imprensa representativa neste novo cenário cultural de massas. Apontando assim que a temática do crime, embora também elaborada graciosamente e com análises ponderadas pela "grande arte", eram caracteristicamente encabeçadas pela "arte popular" de uma maneira maledicente ao progresso positivo da análise do criminoso ${ }^{23}$.

Ora, não é, por certo, entre o amontoado dos pequenos delitos quotidianos que sobressaem as fisionomias monstruosas ou loucas e, por vezes, geniais que, tornadas populares e minuciosamente descritas pela imprensa cotidiana e pela crônica judiciária, são definitivamente fixadas pela fantasia de um artista num drama, romance ou num melodrama. Os crimes, atroz ou sentimentalmente aperfeiçoados e destinados à imortalidade da grande arte, são explorados primeiramente pela arte popular nas suas mais características manifestações. [...] caçadas nos centros urbanos pela imprensa cotidiana e pelo jornal ilustrado, vão, raros e pálidos esboços, maravilhar ingênuos e rústicos espectadores. (FERRI, 2001, p. 25)

O jornal substitui-se aos lamentos por um sou, através da minuciosa crônica da cidade e dos tribunais, e sobretudo pelos seus folhetins. Esses romances de jornal não são, nove vezes entre dez, senão enfeite fantasista sobre o esboço banal dos crimes engendrados. Tornados uma especialidade comercial da literatura francesa, [...] fornecem, em toda a parte, em cenas populares, os assuntos de seus espetáculos à sensação popular. [...] é certamente uma triste educação que, após muitos anos, o teatro e o jornal vêm dando ao povo, contando-lhe, exaltando-lhe mesmo indiretamente, os mais atrozes malefícios, dando, a estes, a honra de correspondências telegráficas e de descrições as mais minuciosas. (FERRI, 2001, p. 26)

23 Em Ferri parece haver uma clara diferenciação entre "alta" e "baixa" literatura, sendo esses patamares artísticos concedidos de acordo com a qualidade ou tratamento cedido ao assunto. 
O crime, objeto de estudo e ponderação tanto da criminologia quanto da literatura, vira espetáculo ou sensação popular através dos folhetins e furos jornalísticos, sendo esses romances maledicentes e viciosos "todo-poderosos sobre a imaginação e sobre os sentimentos do povo" (FERRI, 2001, p. 26) em relação ao assunto. Apesar de reconhecer o papel do público, uma entidade exigente com gostos próprios, Ferri parte do princípio de que o jornal e sua literatura deveriam resgatar aquele papel de educador desta população de inclinações degeneradas ${ }^{24}$. Em um movimento muito próximo ao que Baudelaire (2003) chamou de "utilitarismo literário" 25 , Ferri propõe que a literatura deveria servir-se das observações científicas no intuito de melhor retratar o personagem criminoso de acordo com as conclusões da antropologia criminal.

Não só isso, essa literatura "regenerada" deveria mesmo servir, assim como a ciência, ao propósito de submeter a arte "ao bisturi da anatomia física ou moral, e à lupa da sociologia, para procurar seguir, pela indução, os remédios positivos da higiene e da medicina sociais" (BAUDELAIRE, 2003, p. 22), angariando uma função de incutir em seu publico leitor as novas concepções da Escola Positiva de Direito Penal que repensavam a relação entre o criminoso e a sociedade.

Neste sentido, Ferri procurou atualizar seu discurso de sociólogo higienista e suas inclinações ideológicas caracteristicamente socialistas ${ }^{26}$ referindo-se ao mercado literário e à literatura de crime que circulava na Europa - mas também no Brasil - do momento. Conciliando sua necessidade analítica de compreender o criminoso (ou todo ser humano) enquanto o produto da soma de suas características hereditárias e do meio social em que vive e assim retirando o livre-arbítrio da população de criminosos que eram retratados por essas histórias; com o objetivo de despertar o público leitor para aqueles miseráveis que, vítimas do meio social que os condicionam, acabam por sofrer as consequências sociais do mundo burguês capitalista excludente no qual estavam inseridos.

Passamos rapidamente em revista toda uma multidão sanguinária e monstruosa de criminosos. A arte emprestou muitas vezes a esses degenerados as cores brilhantes de sua paleta e excitou a emoção pública a favor de seres dignos de piedade sem dúvida, mas menos dignos de uma piedade simpática que uma outra multidão, seja, a dos desgraçados que permanecem honestos, malgrado os espasmos e a degenerescência da miséria, da fome de ocasião e da fome crônica. Esses permanecem fiéis, em meio aos piores tormentos da alma, ao sentimento humano e social, contra o qual a violência e sua última

\footnotetext{
24 Papel doutrinário que, segundo Kalifa, já teria sido superado pela economia de mercado literário.

25 Sendo este aquela literatura que se põe caracteristicamente a serviço de uma ideologia e não da contemplação do "Belo" artístico.

26 Ferri foi um importante ativista político filiado ao Partido Socialista Italiano da época.
} 
revolta desesperada, o seu supremo protesto é, quando muito, o suicídio. A arte não tem senão glorificado demasiadamente os criminosos: é preciso que, de agora em diante, ela volte a sua luz radiosa para a multidão dos infelizes. [...] Não vimos senão muitos criminosos violentos e horríveis de miséria moral e de miséria física ou ainda de uma sábia perversidade, covarde e abjeta, no teatro e no romance. Se por muito tempo "a livre concorrência" e o egoísmo sem entranhas infiltraram nas veias, no coração e no cérebro dos homens o vírus da violência, também por muito tempo glorificaram-se ou suprimiram-se violentamente os violentos, segundo eles fossem úteis ou não aos interesses da classe [...]. De modo que a arte nascida neste meio brutal devia fatalmente projetar seus raios brilhantes sobre a pessoa do criminoso. [...] A multidão, a multidão: é nela que está a fonte das inspirações e dos tormentos. (FERRI, 2001, p. 213-214).

A multidão figura então como um corpo de elementos degenerados que precisam ser salvos por um raio de luz que venha de cima e "desça aos antros úmidos ou às cavernas [sociais] lamacentas onde seres, nossos semelhantes, vegetam amontoados" (FERRI, 2001, p. 215). Podendo esta iluminação ser propagada pela própria imprensa, uma vez que esta se responsabilize pelo que publica em nome da regeneração. Pois aquela literatura maledicente que é publicada sobre o crime cotidianamente no jornal, fantasia dos cronistas que tornavam sensacionais noções "errôneas" sobre o criminoso, seria considerada por Ferri um dos elementos sociais propagadores da degeneração desta população. Ajudando assim a despertando os "micróbios do mundo do crime" (FERRI, 2001, p. 23) naquele povo sujeito a esta "patologia social que a consciência coletiva [ou a literatura] apenas pressente, uma vez que ele [o micróbio] se tornou crônico" (FERRI, 2001, p. 23). Germe de doença infecciosa e socialmente propagada que é alimentada pelo jornal, uma vez que esta necessidade mercadológica do sensacional nutre uma curiosidade mórbida de seu leitor sem se preocupar com as consequências sociais desta dieta literária.

Esta constante excitação da curiosidade pública aviva, revive por uma sugestão inconsciente, as lembranças hereditárias dos instintos criminais, apenas recobertas de um ligeiro verniz de civilização, ainda completamente impregnada das violências individuais e coletivas. E, contudo, as mais sublimes virtudes, os sacrifícios mais constantes, as privações mais atrozes permanecem ignoradas do grande público, e passam, entre a desatenção geral, ou provocando apenas um movimento de piedade, diante do rápido caleidoscópio da imprensa cotidiana. (FERRI, 2001, p. 27).

Saindo do laboratório e dos estudos de caso para pensar, entre outras questões relativas a esta literatura condenada, a relação entre o crime e o jornal, é que a publicação da obra Os criminosos na arte e na literatura de Enrico Ferri veio demonstrar uma tendência socializante do discurso cientificista. Escapando do ambiente plenamente acadêmico e 
biologista, o criminalista italiano iniciou uma tendência que viria mesmo fazer escola no Brasil. Pois a uma atitude de análise similar se dedicou também Inaldo de Lyra NevesManta, psiquiatra brasileiro que publicou um livro na década de 1920 cujo intuito era mesmo o de analisar as literaturas que chamou de morbígenas, focando-se inclusive na figura de João do Rio ${ }^{27}$.

Neves-Manta chega a uma posição similar à de Ferri a respeito dessas literaturas que tomam o escabroso como motivo de causar sensação. Perguntando-se se há uma literatura mórbida, enfermiça, doente, chega logo à conclusão de que "Não. Há uma literatura morbígena. O que quer dizer que toda obra de arte é sã: os olhos leigos dos homens é que as tornam enfermas" (NEVES-MANTA, 1976, p. 53). Propondo então que, afinal de contas, a literatura em si não é doente. Degenerado é o seu autor, sendo a literatura "reflexo sempre de uma criatura, do criador [...]" (NEVES-MANTA, 1976, p. 54), mas também o é o olhar de leigo daqueles que a leem, público cuja inclinação à reviver suas memórias hereditárias atávicas Lombroso e Ferri se preocuparam em investigar. Concluindo assim o psiquiatra brasileiro que:

Nenhuns romances [...] possuem um lastro mórbido, mas patagnomônico: o romance, como qualquer obra de arte, não é assim uma peça enfermiça, porém algo capaz de tornar indivíduos sãos em doentes. (NEVES-MANTA, 1976, p. 53).

Enquanto manifestação de uma degeneração física e moral de seus autores e ao mesmo tempo - embora não um objeto enfermo por si só - responsável por despertar instintos criminosos naqueles leitores já pré-sugestionados, aquela literatura sensacional que acha no escabroso e no crime seu motivo literário parece figurar como agente de transmissão de doenças do espírito no discurso de alguns membros influentes da ética da regeneração.

Assim, a antropossociologia do crime, apoiada em aparatos da medicina legal e da ideologia da higiene, vem tornar a literatura - enquanto aspecto social de transmissão ou de evidenciação - um fator importante na determinação da criminalidade. Tornando aquele gosto do povo pelas literaturas de crime um fator indiciário daquela condição criminal que se queria ver associada ao povo. Fator que contribuiria para justificar aquela necessidade de correção dos meios materiais e sociais - a literatura inclusa - nos quais conviviam cotidianamente essa população híbrida e passível de doenças físicas e morais.

Afinal, como propôs Ferri, a "arte, com justo título, teve sempre a função social de prever as novas direções da consciência humana e de as tornar populares" (FERRI, 2001, p

27 Assim como Neve-Manta investigou a figura degenerada das neuroses de João do Rio através da análise de sua obra aliada à observações médicas e psiquiátricas de sua constituição física, Ferri também se propõe a uma rápida análise do caráter dos publicadores de histórias que de alguma maneira recendiam sobre crimes. 
18). Posição que lhe permitiria ser vista como indício para uma disciplina sociológica e seus variados pressupostos de análise na busca pelo equilíbrio da saúde social, dentro de determinado universo cultural, onde corpo e mente estão sempre imersos.

Pensando na expressão destas ideias referentes à literatura alinhadas à ética da regeneração, é possível entrever proposições similares a uma contraposição entre um projeto - nada homogêneo, embora essa fosse sua pretensão - de cultura nacional, de um lado. E uma noção enfermiça de cultura populai, que é apontada por Arnoni Prado e que em seu entender caracterizaria discussões no cenário literário do Rio de Janeiro do período. Pensando na classe ilustrada, referindo-se tanto aos corolários do regime quanto aqueles que lhe eram insubmissos, o crítico procura mostrar como uma espécie de retórica comum ao campo literário procurava instaurar a importância da literatura enquanto instrumento de educação do povo brasileiro e transformação da realidade do Brasil. Instrumento que se pretendia neutro, mas que por fim iria acabar por consagrar aquelas suas manifestações que, de alguma maneira, procuravam seguir as tendências do regime dentro de uma ideia de modernização. Consagração que, entretanto, em nada impediria os autores mais obscuros de continuar a acreditar nesta retórica fantástica.

A contrapartida é a rearticulação ideológica de todo um ciclo de defesa da unidade nacional cujo objetivo básico é assumir a modernização do país tendo como pressuposto a homogeneidade da cultura. Ou seja: a manipulação de uma nova retórica vai deslocar o compromisso da literatura para a esfera de expressão das elites, assimilando-a ao discurso mais amplo que sustenta, nos diversos níveis, a precedência das metas da cultura nacional sobre os interesses da cultura popular. (...) Nesse sentido, próximo do espírito autoritário que sacraliza o saber das elites, o espaço da literatura tende a se definir, no projeto restaurador da Primeira República, como uma instância mediadora que assume a neutralidade para diluir a crise, colhendo, assim, a contrapartida de que a ignorância do povo justifica a necessidade de dirigi-lo e educa-lo do alto. (PRADO, 2010, p. 20)

Ignorância e mau gosto figurando aqui como características de uma mesma face cultural. Pelo menos a partir do momento em que se procura ponderar essa oposição entre cultura nacional e cultura popular no âmbito de nossa discussão. Compreendendo, de um lado, aquela literatura de jornal ligada ao sensacional e ao crime - fruto de um processo complicado de emersão da cultura de massas no meio literário - como justamente algo articulado em torno daquilo que poderíamos considerar como expressão da cultura $\operatorname{popular}^{28}$. E, de outro, a categorização desta literatura enquanto morbigína, uma expressão da luta pela homogeneização cultural que era proposta em determinada retórica literária e

28 Manifestação literária feita para corresponder às expectativas do povo. 
social aliada ao regime da regeneração e que alimentaria o campo de tensão do universo cultural do Rio de Janeiro do momento.

Assim, enquanto arte contaminada passível de contágio, a literatura de crime poderia figurar como força de expressão de tendências contrárias a homogeneidade cultural pretendida por um projeto nacional da camada ilustrada. Embora seja, de certa maneira, resultado negativo destas mesmas tendências que criminalizavam essas manifestações literárias, tornando-as sensação do momento e assim contribuindo para sua emergência no cenário cultural da Primeira República do Brasil.

\section{Conclusão}

No intuito de pensar as tensões do campo cultural e artístico do início do século XX, neste artigo procuramos destacar a relação entre uma "cultura da regeneração" que propunha pensar e reorganizar sua sociedade, com uma "cultura de massa" que transformava o meio jornalístico.

Como procedimento, nos propomos apresentar alguns comentários em torno daquelas notícias sensacionais sobre crimes que eram publicadas, juntamente com histórias ficcionais com a mesma temática, nos jornais do início do século XX no Brasil. Às quais poderiam, de alguma maneira, compartilhar elementos de um imaginário social a respeito do crime e do criminoso que pareci vigorar no momento.

Ao mesmo tempo, procuramos refletir a respeito da maneira com que esse conteúdo sensacionalista dos jornais poderia ter sido recepcionado tanto pelo público leitor comum como por certa parcela da intelectualidade pactuada com a moral da regeneração. Observando a fala de uma figura representativa do próprio jornal (João do Rio) e também de alguns representantes influentes das correntes cientificistas do momento, procuramos compreender uma possível influência "maligna" que era atribuída a estas publicações. Mas também uma função social edificadora que era conferida aos jornais - embora estes não se deixassem orientar por ela -, sempre no intuito de resgatar ou regenerar a população doente (do Brasil e da Europa) e assim sanar os problemas nacionais.

Assim, concluiu-se que esta relação entre os diferentes discursos integrantes de um mesmo universo social parecia buscar na emersão do povo, sob variados sentidos e significados, uma justificativa para sua ação diante da sociedade. Seja nos ditames de uma ideologia da higiene oficializada pela elite republicana, à qual procurava tornar científica a administração de uma sociedade (talvez no intuito de legitimar sua autoridade sobre a 
classe subalterna); seja nas disposições dos novos mecanismos do jornalismo aliados ao paradigma representativo da cultura de massas que parecia emergir no momento.

Tendências discursivas que, por realidade ou proposição, acabavam por gerar comportamentos ou estimular posições nos diferentes níveis da sociedade. As quais, achando na figura do crime e do criminoso uma maneira de adequar suas necessidades que embora diferentes muitas vezes pareciam beberem de fontes parecidas -, poderiam ser entendidas como tendências que apontavam para uma imagem parecida a respeito do povo brasileiro. E que não raramente retiravam o livre-arbítrio deste povo, entidade generalizada nos discursos sociais, passando a considerá-lo como uma soma de fatores de influência biológica e social.

\section{Fontes Documentais}

Gazeta de Notícias, Rio de Janeiro, 1 ago. 1908.

Gazeta de Notícias, Rio de Janeiro, 2 ago. 1908

Gazeta de Notícias, Rio de Janeiro, 5 set. 1908.

Gazeta de Notícias, Rio de Janeiro, 26 set. 1908.

\section{Referências}

BAUDELAIRE, Charles. Ensaios sobre Edgar Allan Poe. São Paulo: Ícone, 2003.

CHALHOUB, Sidney. Cidade Febril. São Paulo: Cia das Letras, 2006. . Trabalho, lar e botequim. 2. ed. Campinas: Unicamp. 2001.

EL FAR, Alessandra. Páginas de sensação: literatura popular pornográfica no Rio de Janeiro (1870-1920). São Paulo: Companhia das Letras, 2004.

FERRI, Enrico. Os criminosos na arte e na literatura. Porto Alegre: Ricardo Lenz, 2001.

KALIFA, Dominique. Crime scenes: criminal topography and social imaginary in Nineteenth-Century Paris. French Historical Studies, Durham, v. 27, n. 1, p. 175-194, 2004. 


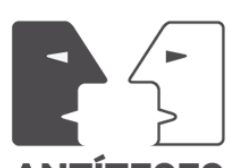

ANTÍTESES

KALIFA, Dominique. História, crime e cultura de massa. Topoi, Rio de Janeiro, v. 13, n. 25, p. 185-192, jul./dez. 2012.

MEYER. Marlyse. Folhetim: uma história. São Paulo: Companhia das Letras, 1996.

NEEDELL, Jeffrey. Belle Époque Tropical. São Paulo: Cia das Letras, 1993.

NEVES-MANTA, Inaldo de Lyra. $A$ arte e a neurose de João do Rio. 5. ed. Rio de Janeiro: Francisco Alves, 1976.

PORTO, Ana Gomes. Novelas sangrentas: literatura de crime no Brasil (1870-1920). Campinas: Unicamp, 2009.

PRADO, Antonio. Itinerário de uma falsa vanguarda. São Paulo: Ed. 34, 2010.

RIO, João do. A alma encantadora das ruas. São Paulo: Companhia das letras, 2008.

SCHWARCZ, Lilia Moritz. O espetáculo das raças: cientistas, instituições e questão racial no Brasil 1870-1930. São Paulo: Companhia das letras, 2005.

WILLIAMS, Raymond. O campo e a cidade na história da literatura. São Paulo: Cia das Letras, 1989. 